\title{
Risk Identification and Quantitative Evaluation Method for Asset Integrity Management of Offshore Platform Equipment and Facilities
}

\author{
Yang Tang, (i) ${ }^{1,2,3}$ Jiaxin Yao, ${ }^{1}$ Guorong Wang, (D) ${ }^{1,2}$ Zhidong Zhang, \\ Yufa $\mathrm{He}^{5}{ }^{5}$ and Jiajia Jing ${ }^{4}$ \\ ${ }^{1}$ School of Mechatronic Engineering, Southwest Petroleum University, Chengdu 610500, China \\ ${ }^{2}$ State Key Laboratory of Oil and Gas Reservoir Geology and Exploitation, Southwest Petroleum University, Chengdu 610500, China \\ ${ }^{3}$ Key Laboratory of Oil \&Gas Equipment, Ministry of Education (Southwest Petroleum University), Chengdu 610500, China \\ ${ }^{4}$ Chuanqing Drilling Engineering Company Limited, CNPC, Guanghan 618000, China \\ ${ }^{5}$ CNOOC Research Institute Ltd., Chaoyang, Beijing 100028, China
}

Correspondence should be addressed to Yang Tang; tangyanggreat@163.com

Received 3 November 2018; Revised 21 March 2019; Accepted 8 April 2019; Published 22 April 2019

Academic Editor: Anna M. Gil-Lafuente

Copyright (c) 2019 Yang Tang et al. This is an open access article distributed under the Creative Commons Attribution License, which permits unrestricted use, distribution, and reproduction in any medium, provided the original work is properly cited.

\begin{abstract}
Asset Integrity Management (AIM) technology has been rapidly developed and applied so that it has become a main management technology of offshore platform equipment and facilities. Risk identification and quantitative evaluation method is one of the core contents in the AIM. However, most of the existing methods are qualitative analysis results, simple analysis process, and strong subjectivity, which can no longer meet the development of AIM technology system. By analyzing disadvantages and shortcomings of the existing methods and adapting to the technology requirements of the AIM, a Streamline Failure Mode Effects and Criticality Analysis (SFMECA) was presented to achieve risk identification and quantitative evaluation based on the traditional FMECA and Borda scoring method. Taking a truss crane as a case study, feasibility and operability of the SFMECA were verified effectively with obtaining a detailed and complete analysis worksheet. Compared with their analysis process and worksheet, it was more specific, more comprehensive, and more operable by applying the SFMECA than the traditional FMECA. Moreover, in the SFMECA, failure risk was divided into four categories in detail and quantified separately to better distinguish and evaluate failure effect. Then a comprehensive quantitative evaluation method of four risks was carried out and risk knots in risk priority number (RPN) were obviously reduced, which help to develop more accurate risk management measures. Independent evaluation mechanism of multiple experts or teams is adopted in the SFMECA to make the analysis and evaluation results more objective. So the worksheet obtained through the SFMECA contains more quantitative data, comprehensive information, and objective results, which can better meet technical system of the AIM. Therefore, application of the SFMECA can provide technical support for extension and application of the AIM technology, including risk quantitative analysis, maintenance decision, and integrity evaluation, for offshore platform equipment and facilities.
\end{abstract}

\section{Introduction}

The offshore platform production system is a large and complex integrated system composed by hundreds of equipment and facilities. It is also a process production system with certain series characteristics [1]. Hence, the equipment and facilities assets are the main of capital assets on the offshore platform. The offshore platform production system has some characteristics such as bad working conditions, being inflammable and explosive, high temperature and high pressure, and rigorous process. A statistical and analytical report showed that the causes of explosions and fire accidents in the offshore platform production system were $41 \%$ of equipment and facilities failures, $20 \%$ of operation errors, $12 \%$ of artificial damage, $9 \%$ of natural disaster, and $18 \%$ of unknown reasons in the past 50 years around the world [2]. 
Therefore, more than half of major accidents can be prevented if equipment and facilities can be maintained and managed scientifically.

With the rapid development of petroleum and petrochemical industry and the increasingly fierce competition in the international market, related enterprises need to continue to strengthen the production safety management and reduce the cost of production in the process of maximizing the benefit of the assets. In 2006, the concept and theory of AIM were first proposed by DNV (Det Norske Veritas), BV (Bureau Veritas), and ABS (American Bureau of Shipping) to achieve health management and risk control for highrisk equipment and facilities in petroleum and petrochemical industry [3]. In recent years, the system and technology of AIM have been continuously developed and perfected, and now it has been gradually applied to the management of equipment and facilities such as refineries, chemical plants, and offshore platforms and has achieved good economic and social benefits.

Risk identification and evaluation is one of the key contents in the AIM of the equipment and facilities. There are a lot of risk analysis and evaluation methods of the equipment and facilities, including Failure Mode Effect and Criticality Analysis (FMECA), Hazard and Operability Analysis (HAZOP), Fault Tree Analysis (FTA), Event Tree Analysis (ETA), and Human Reliability Analysis (HRA) [4]. FMECA is usually chosen as risk identification and evaluation method in the AIM of equipment and facilities. As we all know, procedures for conducting FMECA were described in US Armed Forces Military Procedures document MIL-P-1629 in 1950s [5]. It is a pioneer of risk management. In 1966, NASA published the first FMECA program and used it in the Apollo plan [6]. Since then, FMECA has been promoted and applied in more industries, and many related research works have been carried out about it. FMECA and FTA (failure tree analysis) were combined by $\mathrm{Li}$ [7] to use the system failure risk analysis for the first time domestically. Chen [8] and $\mathrm{Li}$ presented an improved fuzzy FMECA method on the evaluation of the defect risk of automobile ABS. A new FMECA method for the risk evaluation of locomotive and vehicle failure was proposed by Dinmohammadi et al. [9]. Rahardjo B et al. [10] put forward a new FMECA method for the key production process risk evaluation of edible oil. Peng et al. [11] presented a FMECA method that considered the fuzzy cost for the wind turbine failure risk analysis. Zhou et al. [12] proposed a modified model of failure mode and effects analysis based on generalized evidence theory. FMECA was used by Chen [10] for the dynamic evaluation and risk control of the structural integrity of the aging platform. As mentioned above, there was a series of research works on applications and improvements of FMECA which had been carried out to adapt to different objects, requirements, and applications. However, the improvement of FMECA in these studies is mainly about the adjustment or reduction of its analysis steps and the change of a certain content to adapt to the different application objects. Moreover, the results obtained from FMECA worksheet are mostly qualitative descriptions so that they are not standardized, uniform, and data-poor.
At present, a digital management model of offshore platform is gradually improving so that a large amount of equipment and facilities maintenance management data have been formed. Therefore, the key technologies of AIM for the equipment and facilities on offshore platforms are developing towards datamation and quantification. Moreover, the key technologies and methods should be streamlined and programmed and be concise, so that they can better handle large data and improve the efficiency of analysis. However, with the development and popularization of AIM technology, the existing FMECA methods have not satisfied the needs of the risk identification and quantitative evaluation under these circumstances of big data age. Therefore, it is very necessary to study a new risk identification and evaluation method to fulfill the requirements of the application of the AIM technology.

The paper is organized as follows. In Section 2, the shortcomings of the existing FMEA and FMECA are analyzed. Based on the traditional FMECA, a new risk identification method is established in Section 3. Then, in Section 4, quantitative evaluation method of comprehensive risk is established based on Borda scoring method. In Section 5, a case study on the truss crane is performed to verify the new methods. Finally, Section 6 provides some discussions and conclusions.

\section{FMEA and FMECA}

Failure Mode and Effects Analysis (FMEA) is the first systematic technology for failure analysis of technical systems, including process systems, mechanical systems, and electronic systems. FMEA is mainly used to identify, describe, and inspect the potential failure modes, failure causes, and effects analysis in the system and process. It was used firstly to find problems in the military system and it was also applied in aerospace and nuclear technology. Now, it has been applied to the automobile and oil and gas industries [13]. The traditional method of FMEA is used to analyze the function, failure mode, and influence of each component in the technology system and get the FMEA record chart, as shown in Table 1. In the traditional RCM analysis, in order to concentrate on the maintenance resources effectively and reduce the analysis workload, it only needs the detailed FMEA analysis to the key items and makes the corresponding maintenance strategies according to the results of FMEA.

Failure Mode Effects and Criticality Analysis method (FMECA) is the development of FMEA technology in the application. It contains two parts, Failure Mode and Effect Analysis (FMEA) and Criticality Analysis (CA). It is one of the most basic, most effective, and most important analytical techniques in the current reliability engineering [14]. The implementation of FMECA for mechanical systems is mainly aimed at achieving these objectives as follows.

(a) Discovery of all failure modes for every item in the system

(b) Cause analysis of every failure mode

(c) Effect analysis of every failure mode

(d) Determination of the occurrence probability of each failure mode 
TABLE 1: Example FMEA worksheet.

\begin{tabular}{|c|c|c|c|c|}
\hline Number & Function & Failure mode & Failure cause & Failure process and effect description \\
\hline
\end{tabular}

TABLE 2: FMECA Record example (SN: serial number; FU: function; FM: failure mode; FC: failure cause; FE: failure effect; FD: failure detection; FP: failure probability; FS: failure severity; DD: detection difficulty; RPN: risk priority number).

\begin{tabular}{|c|c|c|c|c|c|c|c|c|c|}
\hline \multicolumn{3}{|c|}{ Item description } & \multicolumn{3}{|c|}{ Failure effect description } & \multicolumn{4}{|c|}{ Failure risk analysis } \\
\hline $\mathrm{SN}$ & $\mathrm{FU}$ & FM & FC & FE & FD & $\mathrm{FP}$ & FS & DD & RPN \\
\hline (1) & (2) & (3) & (4) & (5) & (6) & (7) & (8) & (9) & (10) \\
\hline
\end{tabular}

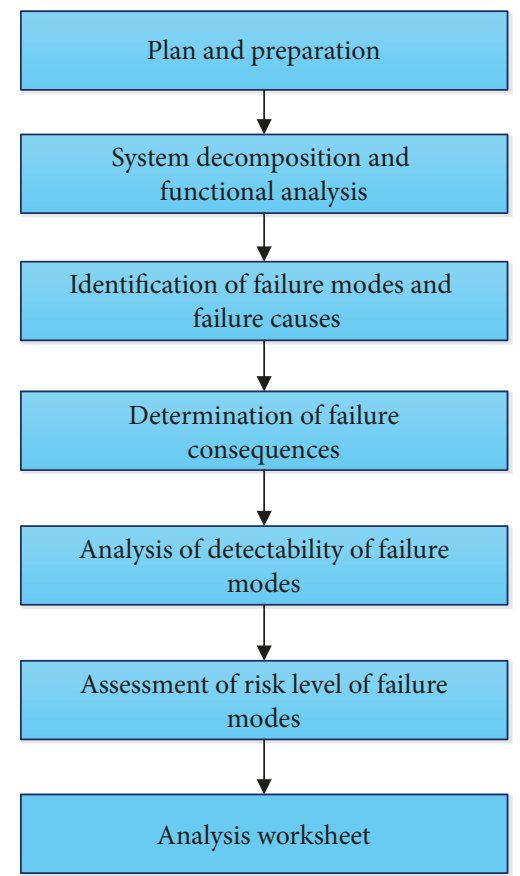

FIgURE 1: Analysis flow chart of FMECA.

(e) Determination of the severity of each failure mode

(f) Evaluation of the risk related to each failure mode

(g) Formulation of measures or methods of risk reduction.

The conventional FMECA is a simple technique. It does not need to establish any special algorithm. Its analysis steps can be divided into seven steps, as shown in Figure 1.

According to the analysis flow chart of FMECA, step by step analysis, the FMECA worksheet can be worked out, as shown in Table 2. The FMECA worksheet can be used for item design analysis, maintenance decision, and risk management of Reliability Centered Maintenance (RCM).

Through the requirement analysis of the implementation of AIM technology for the equipment and facilities on offshore platform, their shortcomings are summarized as follows [13, 14].

(1) Failure mode classification is not subdivided, for example, obvious failure, hidden failure, and burst failure, which maybe lead to an unscientific and inaccurate implementation of failure detection, maintenance decision, and risk management.

(2) Most of the risk identification processes only consider the single or general risk related to security or economy. Moreover, the failure risk is not subdivided and distinguished such as the high-risk oil and gas equipment which can bring about safety, environmental, economic cost, maintenance cost, reputation impact, and so forth.

(3) Lack of the comprehensive risk evaluation method of the failure mode and insufficiency of risk level make it impossible to distinguish similar risks accurately.

(4) In analysis process of the existing FMECA, the opinions of many experts or many teams are not taken into consideration so that the analysis process is not rigorous and the analysis result is limitation.

Hence, contraposing the shortcomings of the existing FMECA methods and by combination, a new FMECA that is more specific, more comprehensive, and more operable should be studied to meet the application requirements of the AIM technology for the equipment and facilities on offshore platform.

\section{Establishment of Streamline Failure Mode Effects and Criticality Analysis}

In order to fulfil the application requirements of the AIM technology, the characteristics of the equipment and facilities on the offshore platform were analyzed. Then, combining the existing FMECA methods, a Streamline Failure Mode Effects and Criticality Analysis (SFMECA) method for the equipment and facilities on the offshore platform was proposed, as shown in Figure 2.

Step 1 (collection of data and information). The data and information required for the SFMECA analysis are as follows. Before performing the analysis, the collected data need to be audited to assess its consistency and integrity, including process description, process flow chart (PFD), causality diagram, equipment account, safety related evaluation report (work out acceptance criteria), equipment classification list, major equipment specification case book, equipment operation manual, current maintenance plan and maintenance procedure, main equipment history failure, and maintenance record (MAXIMO system or SAP). 


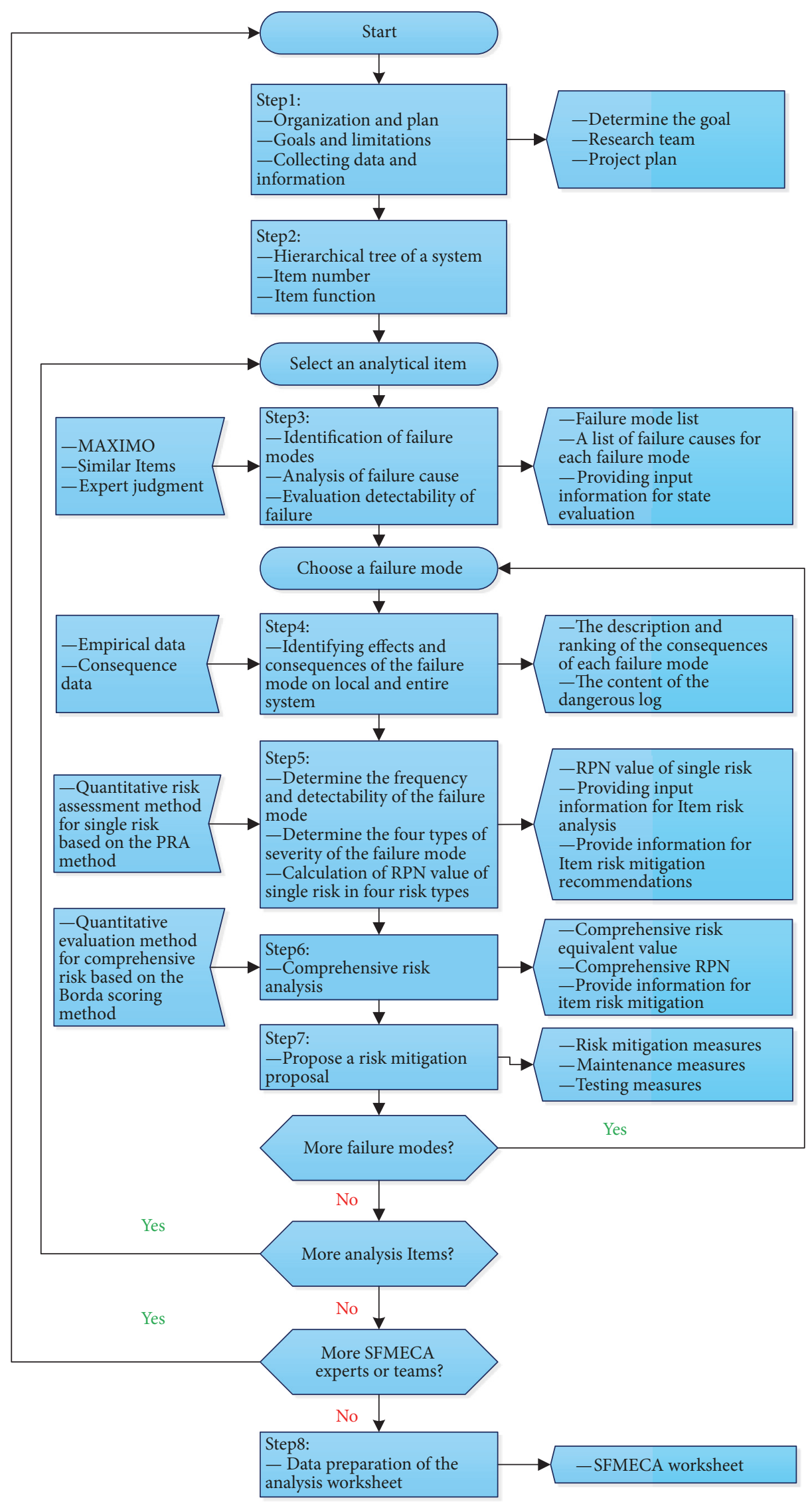

FIGURE 2: SFMECA analysis flow chart. 
TABLE 3: Evaluation criteria of the failure probability $\left(s_{p}\right)$.

\begin{tabular}{|c|c|c|}
\hline Quantitative score & Frequency description & Explain \\
\hline \multirow{3}{*}{5} & \multirow{3}{*}{ Very high } & (1) The failure is likely to happen. \\
\hline & & (2) Annual occurrence probability $\left(>10^{-2}\right)$. \\
\hline & & (3) Records or experience in the industry shows that it has occurred in 0.5 years. \\
\hline \multirow{3}{*}{4} & \multirow{3}{*}{ High } & (1) The failure is likely to happen. \\
\hline & & (2) Annual occurrence probability $\left(10^{-3} \sim 10^{-2}\right)$. \\
\hline & & (3) Records or experience in the industry shows that it has occurred in $0.5 \sim 2$ years. \\
\hline \multirow{3}{*}{3} & \multirow{3}{*}{ Secondary } & (1) The failure can happen. \\
\hline & & (2) Annual occurrence probability $\left(10^{-4} \sim 10^{-3}\right)$. \\
\hline & & (3) Records or experience in the industry shows that it has occurred in $2 \sim 7$ years. \\
\hline \multirow{3}{*}{2} & \multirow{3}{*}{ Low } & (1) The failure may not happen. \\
\hline & & (2) Annual occurrence probability $\left(10^{-5} \sim 10^{-4}\right)$. \\
\hline & & (3) Records or experience in the industry shows that it has occurred in 7 15 years. \\
\hline \multirow{3}{*}{1} & \multirow{3}{*}{ Very low } & (1) The failure will hardly happen. \\
\hline & & (2) Annual occurrence probability $\left(<10^{-5}\right)$. \\
\hline & & (3) Records or experience in the industry shows that it has not occurred in 15 years. \\
\hline
\end{tabular}

Step 2 (establishment of hierarchical tree and function analysis of items). (1) Function diagrams and drawings of the system should be checked and the relationship between different subsystems should be ensured.

(2) A complete component list should be prepared for every subsystem. Each element should be assigned a unique identification number, which is the index number $\left(1^{\text {th }}\right.$ column).

(3) Based on their different functions or purposes, the equipment and facilities should be divided into different subsystems, and subsystems are divided into parts for maintenance.

(4) Defining the main functions of the product $\left(2^{\text {th }}\right.$ column) and determining the evaluation criteria for these functional integrity.

Step 3 (identification of failure mode and cause). The failure mode and cause should be identified for every item. For example, historical data in MAXIMO and SAP management systems of the equipment and facilities on the offshore platform can provide reference for this step.

(1) Analysis of failure mode ( $3^{\text {th }}$ column). All possible failure modes of every functions should be analyzed, including the failure events that have occurred in the same or similar equipment in the same operating environment; in the current maintenance management system, the failure events are being prevented; there is no occurrence but the failure events are most likely to happen.

(2) Analysis of failure modes types ( $4^{\text {th }}$ column). Referring to the RCM theory, the failure types include four types: obvious potential failures, obvious sudden failures, hidden potential failures, and hidden sudden failures.

(3) Analysis of failure causes ( $5^{\text {th }}$ column). All possible causes of failure should be analyzed. The common causes of failure of mechanical equipment may be corrosion, wear, fatigue, overstress, overload, insufficient maintenance, operation error, and so on.
(4) Analysis of failure probability ( $6^{\text {th }}$ column). Based on the related records of existing maintenance detection records and similar items, the failure occurrence probability is counted, or the evaluation value of failure occurrence probability is given by experts. The evaluation criteria of failure probability are described in Table 3.

(5) Analysis of failure detectability ( $7^{\text {th }}$ column). The failure detectability is evaluated according to the failure modes ( $3^{\text {th }}$ column) and the failure types ( $4^{\text {th }}$ column). The related personnel requirements, technical requirements, and detection time are used to evaluate the failure detectability. The evaluation criteria of failure detectability are described in Table 4.

Step 4 (confirmation of failure severity). According to the consequences directly caused by the failure of the offshore platform equipment, the effects of failure modes are divided into safety risk ( $8^{\text {th }}$ column), environmental risk $\left(9^{\text {th }}\right.$ column), economic loss risk ( $10^{\text {th }}$ column), and maintenance cost risk ( $11^{\text {th }}$ column). The evaluation criteria of the failure severity are described in Table $5[15,16]$.

Step 5 (failure risk analysis). One failure mode can lead to more than one consequence, including safety effect, environment effect, economic loss effect, and maintenance cost effect, which can be regarded as four types of risks. Based on the evaluation criteria of failure probability $s_{p}$, failure detectability $\mathrm{s}_{d}$, and failure severity $\mathrm{s}_{s}$, RPN of safety risk ( $12^{\text {th }}$ column), RPN of environmental risk ( $13^{\text {th }}$ column), RPN of economic loss risk ( $14^{\text {th }}$ column), and RPN of maintenance cost risk ( $15^{\text {th }}$ column) can be calculated by adopting the Probabilistic Risk Analysis (PRA) [17, 18].

The risk priority number (RPN) formula for the single risk of failure modes is given as

$$
R P N=S_{s} \times S_{p} \times S_{d}
$$


TABLE 4: Evaluation criteria of the failure detectability $\left(s_{d}\right)$.

\begin{tabular}{lcl}
\hline Quantitative score & Detectability description & Explain \\
\hline 5 & Very high difficulty & Cannot be detected: it cannot be detected by any means. \\
\hline 3 & High difficulty & $\begin{array}{l}\text { Hardly detected: it is almost impossible to be detected or } \\
\text { takes a long time to be detected. }\end{array}$ \\
\hline 2 & Secondary difficulty & $\begin{array}{l}\text { Normally detected: it is normally detected through complex } \\
\text { disassembly, installation, and testing equipment in a long } \\
\text { time. }\end{array}$ \\
\hline 1 & Low difficulty & $\begin{array}{l}\text { Easily detected: it is normally detected in a short time by } \\
\text { simple disassembly. }\end{array}$ \\
\hline
\end{tabular}

According to the RPN value of each failure mode, the risk level of each type of risk that caused system failure can be determined.

Step 6 (analysis of comprehensive risk). Based on the Borda scoring method, a comprehensive quantitative evaluation method is established to calculate comprehensive risk equivalent value $\left(16^{\text {th }}\right.$ column) of the four risk types of one objection. According to the comprehensive risk equivalent value calculated by the comprehensive quantitative evaluation method, a comprehensive risk priority number $\left(17^{\text {th }}\right.$ column) can be worked out [19].

Step 7 (presentation of risk mitigation measures). According to the risk types and risk levels, risk mitigation measures $\left(18^{\text {th }}\right.$ column) are proposed, including measures to correct failure, restore function, or avoid serious consequences [20, 21]. Moreover, the measures that may reduce the frequency of failure modes should be recorded.

Step 8 (formulation of SFMECA worksheet). The process of SFMECA can produce large amount of result information, while the analysis of large or complex objects will run multiple SFMECA processes at the same time [22]. Therefore, the process and results of the SFMECA should be examined and summarized in detail so as to formulate a SFMECA worksheet.

\section{Quantitative Evaluation Method of Comprehensive Risk Based on Borda Scoring Method}

Risk matrix is often used in the risk evaluation of simple objection, but it is easy for risk knot to appear in the evaluation results; that is, two objects with different real risks may have the same risk level. Therefore, this method cannot distinguish the level of risk of complex objects very well. According to the survey, the Borda scoring method is a kind of risk ranking method similar to voting. It can be combined with the frequency and influence degree of risk events to arrange the preorder relationship of risk and has been successfully applied to risk evaluation in [19]. Therefore, the Borda scoring method is chosen to be applied into comprehensive risk calculation of the equipment and facilities on the offshore platform.

In the traditional Borda scoring method, linear summation is often used to calculate Borda value to characterize the scores of evaluation objects. When the number of evaluation criteria is enough in the process of calculating Borda value, the satisfactory results can be obtained and the same Borda value is also less. For the risk evaluation of offshore platform equipment and facilities, the number of evaluation criteria usually is less. If it is calculated by linear addition with the traditional Borda scoring method, the same Borda value is easy to appear, which is not conducive to the identification of risk level and the risk ranking of the evaluated objects. Therefore, the calculation method of Borda value in the traditional Borda scoring method should be improved so as to effectively avoid the same Borda value and reduce the risk knot in the risk priority number. To facilitate the description of the improved Borda scoring method, the following parameters are set as follows.

(1) $R_{i}$ : The $i^{\text {th }}$ evaluated object which is a failure mode, $i=1,2, \ldots n$, where $n$ represents the total number of the failure modes.

(2) $k$ : Risk evaluation criteria, $k=1,2, \ldots m$, where $m$ represents the total number of risk criteria. For example, there are four criteria for risk evaluation, safety risk criteria, environmental risk criteria, economic loss risk criteria, and maintenance cost risk criteria, in SFMECA. $k=1$ represents safety risk criteria; $k=2$ represents environmental risk criteria; $k=2$ represents economic loss risk criteria; $k=2$ represents maintenance cost risk criteria.

(3) $C^{k}\left(R_{i}\right)$ : Under the risk evaluation criteria $k$, the risk equivalent value of failure mode is $R_{i}$.

(4) $N^{k}\left(R_{i}\right)$ : Under the risk evaluation criteria $k$, the number of failure modes is larger than the failure mode $R_{i}$, $i=1,2, \ldots n ; k=1,2, \ldots m$.

(5) $B\left(R_{i}\right)$ : Borda value of the failure mode $R_{i}$.

(6) $O\left(R_{i}\right)$ : Ranking value of the failure mode $R_{i}$.

The calculated formula of $B\left(R_{i}\right)$ can be seen in which $B\left(R_{i}\right)$ is about $N^{k}\left(R_{i}\right)$ decreasing. Therefore, the calculated Borda value can reflect the risk level of an evaluated object, and the overall risk level of the evaluated object can be ranked according to the value of $B\left(R_{i}\right)$. The higher the Borda value the higher comprehensive risk level and that leads to higher risk ranking. 


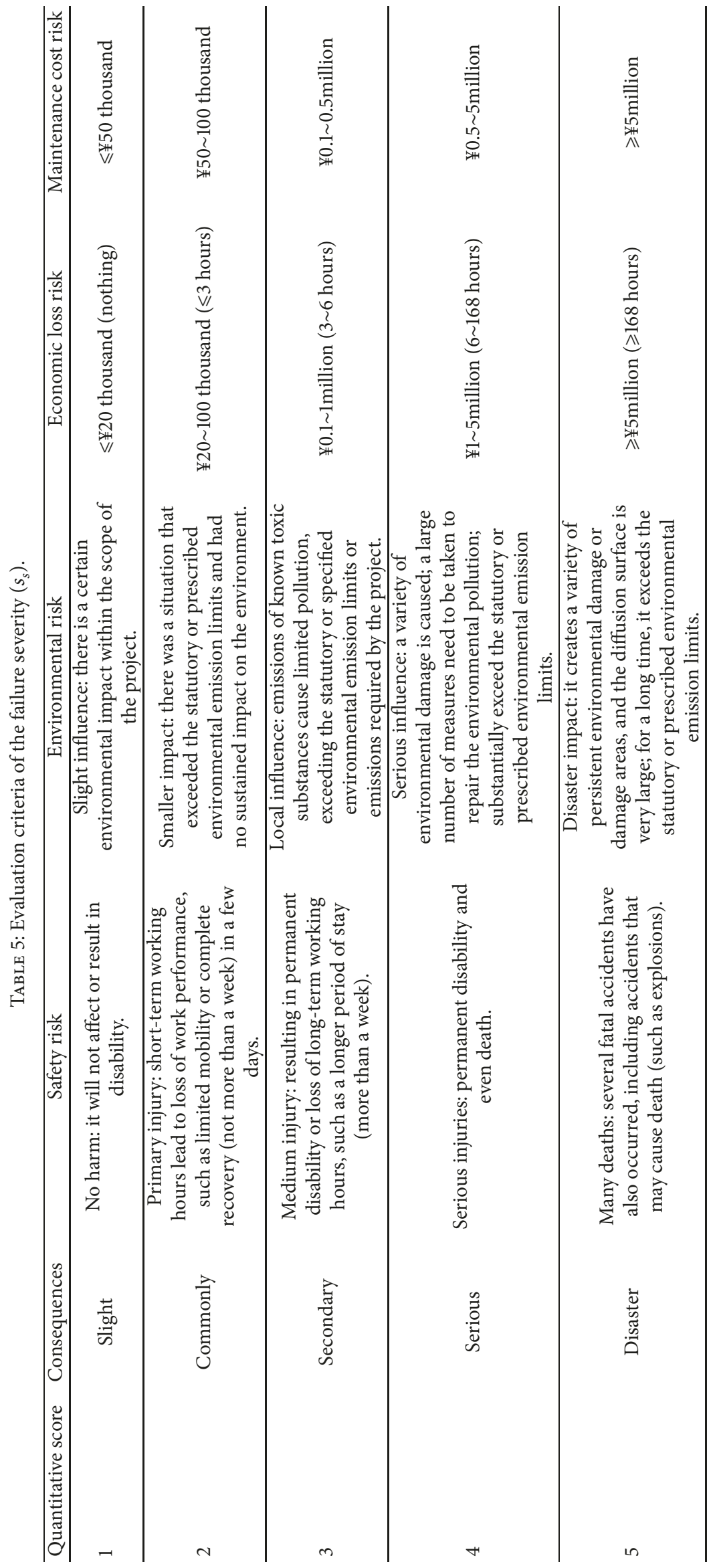


Based on the traditional Borda scoring method, combined with the characteristics of risk evaluation of the offshore platform equipment and facilities, an improved Borda scoring method is established. The detailed calculation steps and contents of the improved Borda scoring method are as follows.

Step 1 (confirmation of the total number of $n$ and the total number of risk criteria $m$ ). The values of $m$ and $n$ are obtained according to the initial data of the SFMECA worksheet.

Step 2 (confirmation of $C^{k}\left(R_{i}\right)$ ). According to the SFMECA worksheet, the risk values of the target are obtained under all kinds of risk criteria, which are $C^{k}\left(R_{i}\right)(i=1,2, \ldots n ; k=1,2, \ldots$ $m)$.

Step 3 (calculation of $N^{k}\left(R_{i}\right)$ ). Its calculation formula is

$$
N^{k}\left(R_{i}\right)=\left|\left\{j: C^{k}\left(R_{i}\right)<C^{k}\left(R_{j}\right), j=1,2, \ldots, n\right\}\right|
$$

where $|\bullet|$ denotes the number of elements in a set.

Step 4 (calculation of $B\left(R_{i}\right)$ ). Its calculation formula is

$$
B\left(R_{i}\right)=\prod_{k=1}^{m}\left(N-N^{k}\left(R_{i}\right)\right), \quad i=1,2, \ldots, n
$$

Step 5 (calculation of $O\left(R_{i}\right)$ ). Its calculation formula is

$$
O\left(R_{i}\right)=n-\left|\left\{j: B\left(R_{i}\right)>B\left(R_{j}\right), j=1, \cdots, n\right\}\right|
$$

where $|\bullet|$ denotes the number of elements in a set.

Step 6 (output of calculation results). Output the result of comprehensive risk equivalent value of the evaluated object $R_{i}$. Then, the calculated comprehensive risk equivalent value and comprehensive risk priority number are filled in a SFMECA worksheet.

\section{Case Study}

Taking a LIUHUA10-1PGC truss crane on an offshore platform as an example, the important functional items of main lifting machinery system (MLMS) were screened out as the analysis objection. Then, the risk identification and risk quantitative evaluation were carried out for the MLMS by applying the SFMECA $[23,24]$. So a SFMECA worksheet of the MLMS was obtained as shown in Table 6.

According to analysis process and results of risk identification and quantitative evaluation of the MLMS, feasibility and operability of the SFMECA method were verified effectively and a detailed and complete analysis worksheet was obtained. From the SFMECA worksheet of the MLMS, we could find that it was more specific, more comprehensive, and more operable by applying the SFMECA than by applying the traditional FMECA. In the SFMECA, failure mode type was divided into four types: obvious type, obvious potential type, obvious sudden type, and hidden type in the $4^{\text {th }}$ column of the SFMECA worksheet. Failure risk was also divided into four categories: safety risk, environmental risk, economic loss risk, and maintenance cost risk, so that failure risk types can be easily identified, which can help to refine scientific risk management. Then, the quantitative evaluation results of four failure risks of the MLMS have been better realized and better distinguished and evaluated failure effect as shown in the $12^{\text {th }}-15^{\text {th }}$ columns of the SFMECA worksheet. Moreover, in the SFMECA worksheet, comprehensive risk equivalent values (CREV) of the four risk types of every failure mode were calculated in the $16^{\text {th }}$ column and the risk knots in comprehensive risk priority number (CRPN) were obviously reduced in the $17^{\text {th }}$ column, which can help the MLMS to develop more accurate risk management measures. Independent evaluation mechanism of multiple experts or teams was adopted in the SFMECA to make the analysis and evaluation results more objective. So the worksheet obtained through the SFMECA contains more quantitative data, comprehensive information, and objective results, which can better meet technical system of the AIM. Drilling pumps and diesel engines in oil fields were also analyzed by the SFMECA method, and their analysis results validate the above conclusions as well. Different equipment and facilities should have different evaluation criteria of failure probability $s_{p}$, failure severity $s_{s}$, and failure detectability $s_{d}$, but in this study it is currently established for the truss crane on an offshore platform. Therefore, in the application of SFMECA, we should pay attention to the fact that it needs to reestablish new different evaluation criteria about failure probability $s_{p}$, failure severity $s_{s}$, and failure detectability $s_{d}$, when a new and different object carries out risk identification and quantitative evaluation.

\section{Conclusion}

Asset Integrity Management (AIM) has become the mainstream system for the security and scientific management of the equipment and facilities on offshore platform. With the implementation of digital management of offshore platform, the AIM system has gradually changed from qualitative to quantitative. But quantitative evaluation still is not realized in the risk identification and evaluation method, which is one of the core technologies of AIM. And its existing methods could not better meet the application requirements of AIM on offshore platform.

In the study, combining with the advantages and shortcomings of the conventional FMECA, a SFMECA method was put forward to achieve the risk identification and evaluation for the equipment and facilities on offshore platform. Taking the truss type crane as an example, the feasibility and operability of the SFMECA were verified effectively. Compared with the existing FMECA methods, the analysis results of SFMECA method are more specific, more comprehensive, and more operable. In the SFMECA worksheet, there are a lot of information and data for the AIM, including function (FU), failure modes (FM), failure mode type (FMT), failure cause (FC), failure detection (FD), failure probability (FP), failure severity (FS), failure detectability (FD), security effect (SE), environmental effect (EE), economic cost effect (ECE), maintenance cost effect (MCE), risk priority number (RPN), 


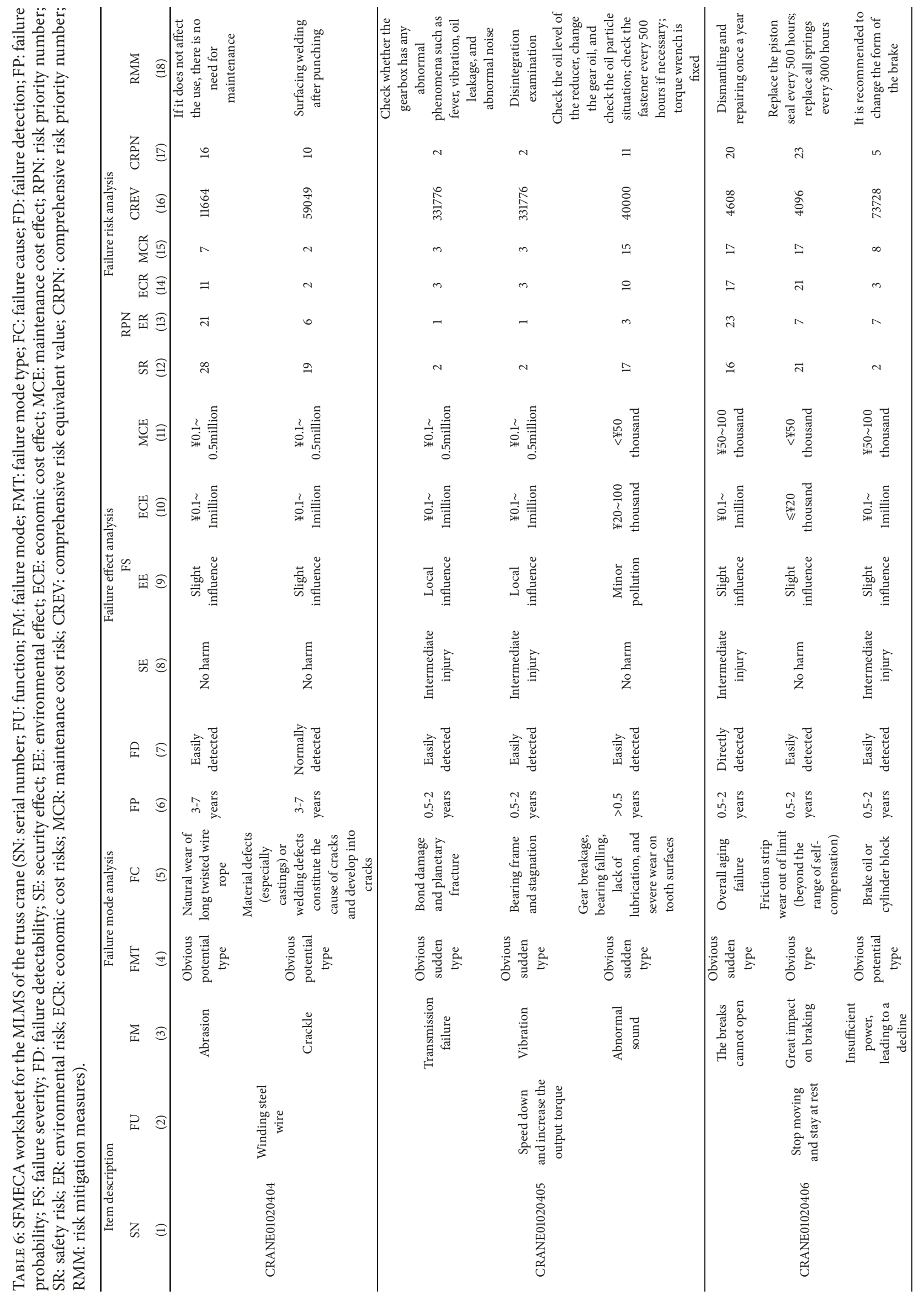




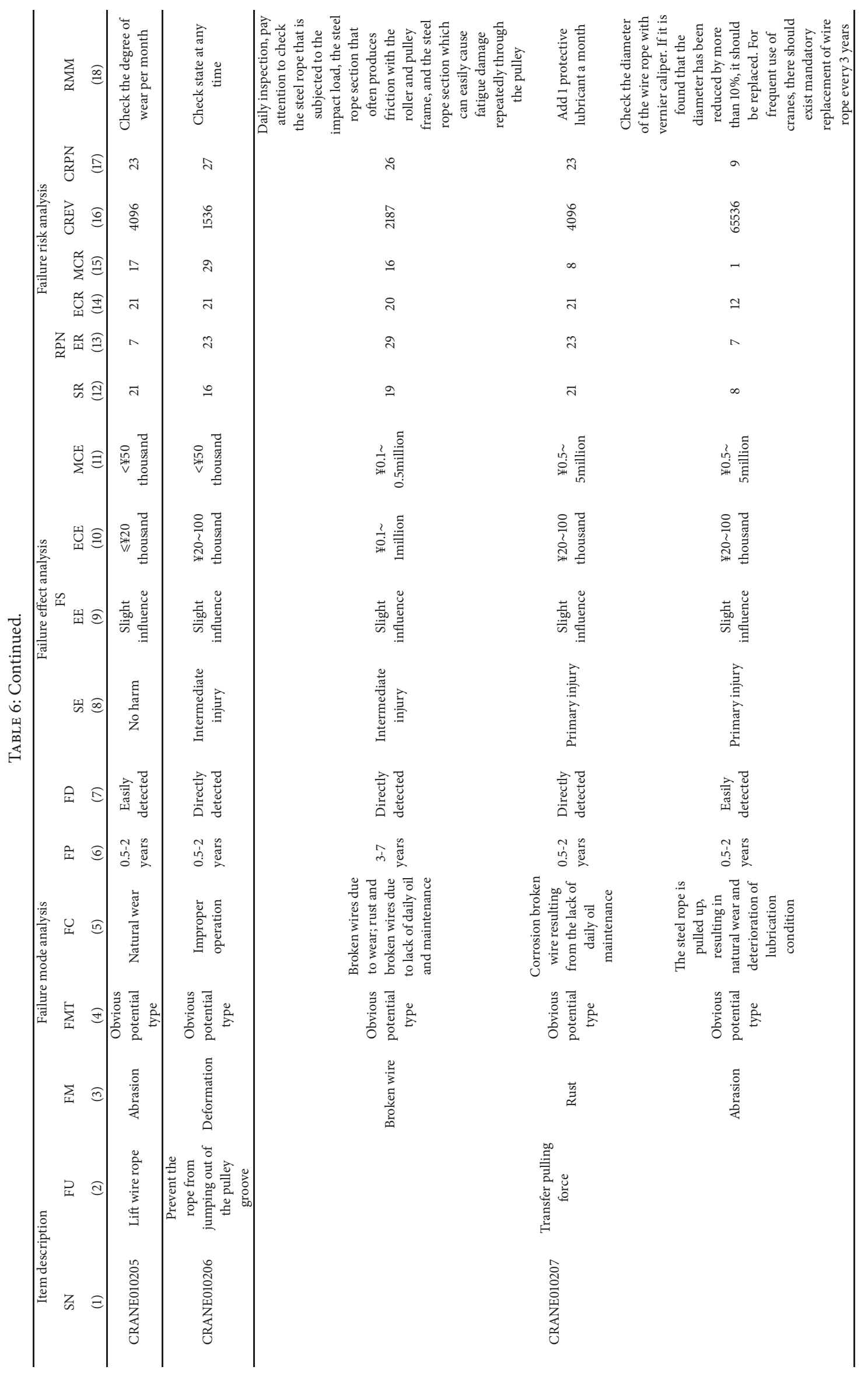




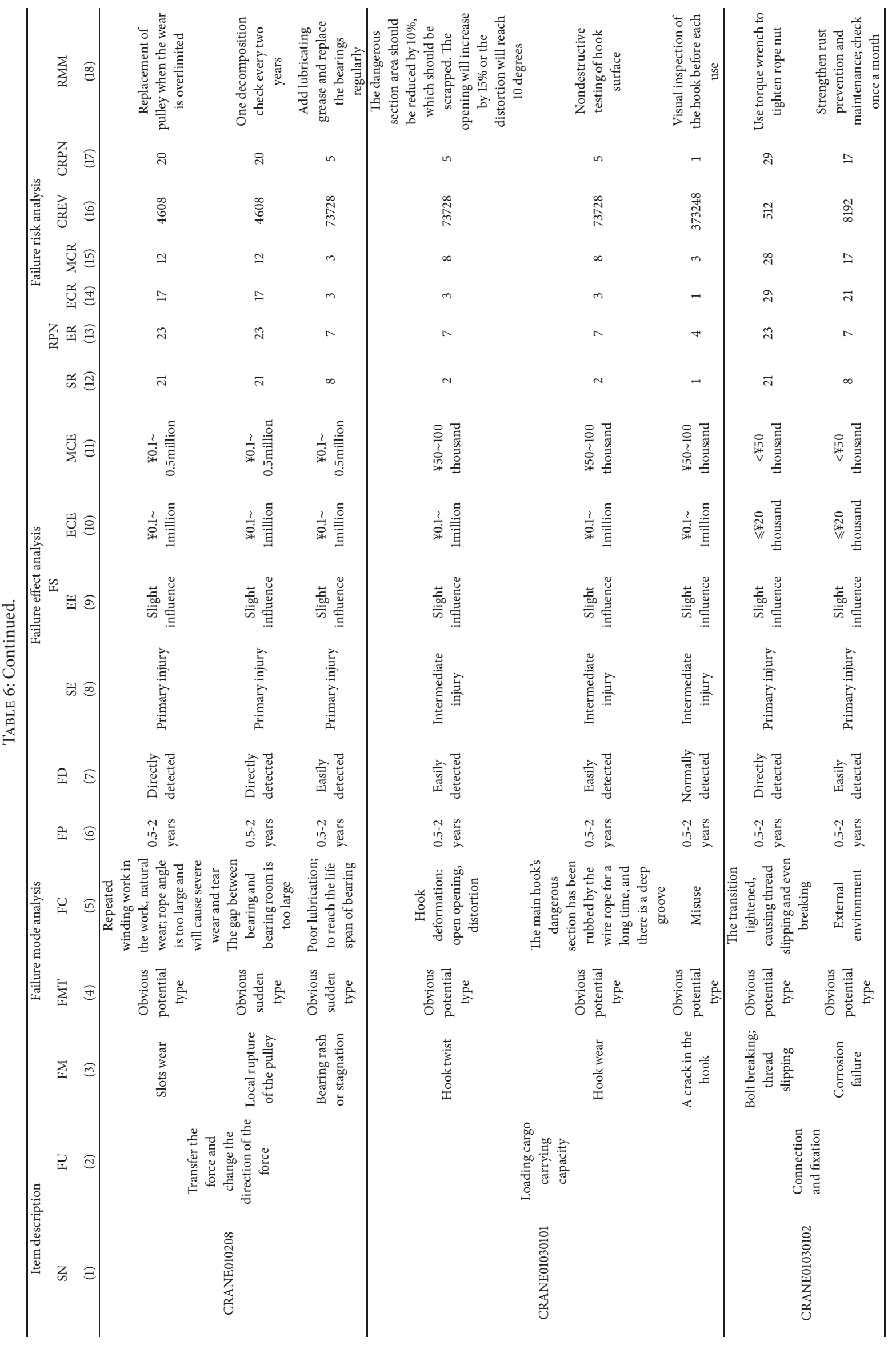




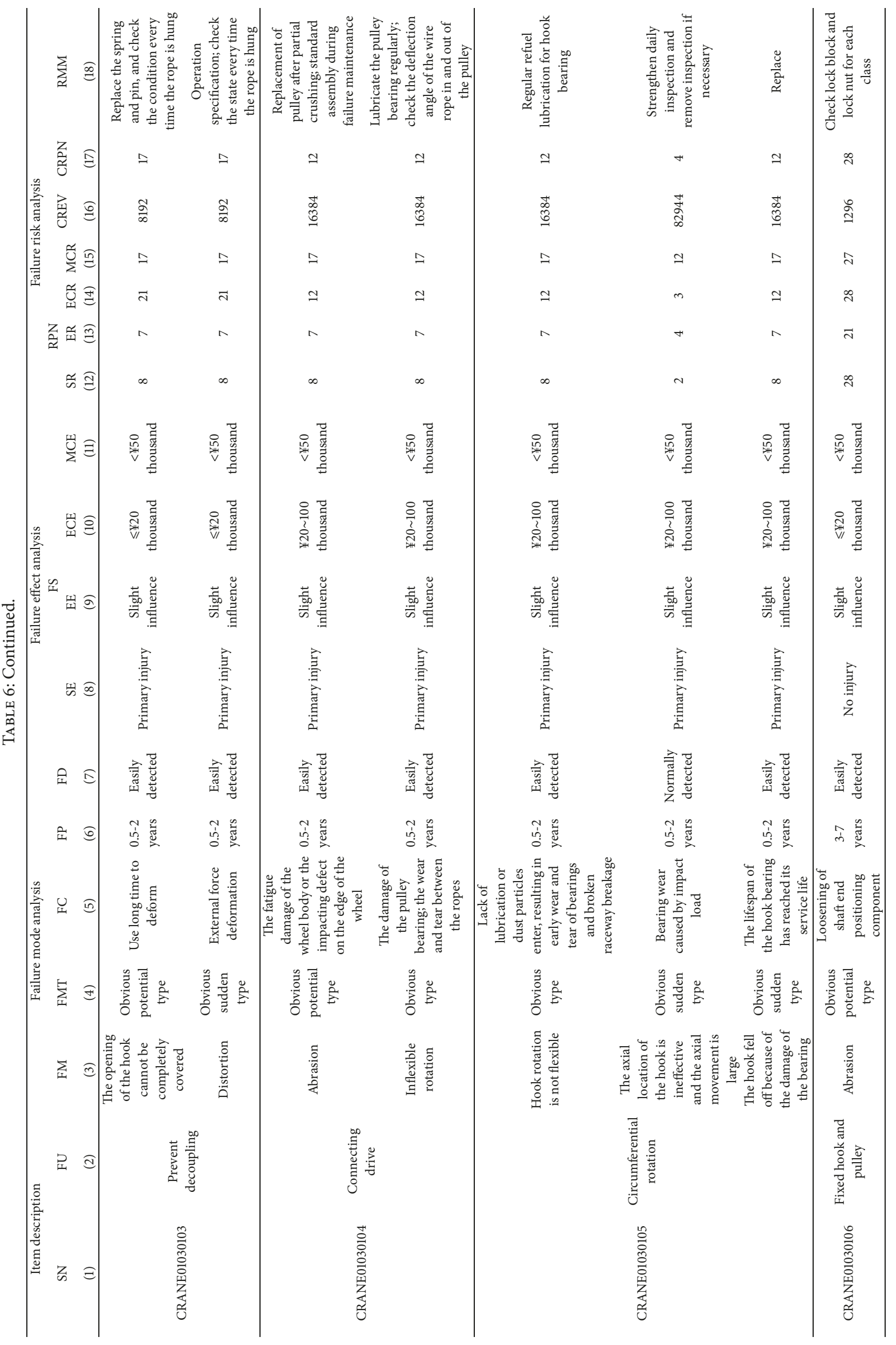


safety risk (SR), environmental risk (ER), economic cost risks (ECR), maintenance cost risk (MCR), comprehensive risk equivalent value (CREV), comprehensive risk priority number (CRPN), and risk mitigation measures (RMM). According to the different risk types and different risk level and risk ranking of the equipment and facilities on offshore platform in the SFMECA worksheet, the risk management and control measures can be optimized according to the different tolerance of the enterprise on the risk, such as attention to personnel safety or environmental pollution. Based on the failure modes, failure mode types, failure causes, and failure consequences in the SFMECA worksheet, scientific maintenance decision and reasonable maintenance measures of the equipment and facilities on offshore platform can be made. Moreover, the SFMECA worksheet can provide data support for the failure diagnosis, state monitoring, health evaluation, and trend prediction of the equipment and facilities on offshore platform. It will be better able to help engineers and managers formulate corresponding management measures. Therefore, SFMECA is a novel and practical method for the AIM of the equipment and facilities on offshore platform.

In the next step, for high-risk equipment and facilities in the whole petroleum and petrochemical industry, the comprehensive risk analysis and the quantitative risk evaluation method of failure modes will be carried out. Moreover, more theoretical and technical supports are going to be presented for the implementation and promotion of the AIM technology based on the analysis results of SFMECA.

\section{Data Availability}

The data used to support the findings of this study are available from the corresponding author upon request.

\section{Conflicts of Interest}

The authors declare that there are no conflicts of interest regarding the publication of this paper.

\section{Acknowledgments}

This work is supported by the National Key Research and Development Program (2018YFC0310201), National Science and Technology Major Project (2016ZX05028-001-006), China Postdoctoral Innovative Talents Support Program (BX20190292), Scientific Research Starting Project of SWPU (no. 2018QHZ017), and Open Fund of State Key Laboratory of Oil and Gas Reservoir Geology and Exploitation (Southwest Petroleum University) (PLN201827).

\section{References}

[1] E. Olsen, S. Næss, and S. Høyland, "Exploring relationships between organizational factors and hydrocarbon leaks on offshore platform," Safety Science, vol. 80, pp. 301-309, 2015.

[2] J. Yang, W. Wang, M. Zhao, B. Chen, O. A. Dada, and Z. Chu, "Spatial distribution and historical trends of heavy metals in the sediments of petroleum producing regions of the Beibu Gulf, China," Marine Pollution Bulletin, vol. 91, no. 1, pp. 87-95, 2015.
[3] B. Lanquetin, J. Goyet, and J. Esteve, "Implementing risk-based inspection on our $\mathrm{F}(\mathrm{P}) \mathrm{SO}$ : from a practical approach to the edge of R\&D," in Proceedings of the Offshore Technology Conference, OTC 07, pp. 409-424, Offshore Technology Conference, Houston, TX, USA, May 2007.

[4] Y. Tang, J. Jing, Z. Zhang et al., "A quantitative risk analysis method for the high hazard mechanical system in petroleum and petrochemical industry," Energies, vol. 11, no. 1, p. 14, 2017.

[5] Procedures for Performing a Failure Mode, Effects and Criticality Analysis, Department of Defense, Washington, DC, USA, 1949.

[6] Procedure for Failure Mode, Effects and Criticality Analysis (FMECA), National Aeronautics and Space Administration, Washington, DC, USA, 1966.

[7] L. Junshan, T. Qingci, and L. Tingxiao, "Computer aided FMECA and FTA integrated analysis," Journal of Beijing University of Aeronautics and Astronautics, vol. 1, pp. 38-43, 1992.

[8] C. Yuzhong, D. Honglei, L. Chenfeng et al., "Risk evaluation of vehicle ABS defects based on modified fuzzy FMECA method," Journal of Automotive Safety and Energy, vol. 7, no. 3, pp. 265271, 2016.

[9] F. Dinmohammadi, B. Alkali, M. Shafiee, C. Bérenguer, and A. Labib, "Risk evaluation of railway rolling stock failures using fmeca technique: a case study of passenger door system," Urban Rail Transit, pp. 1-18, 2016.

[10] B. Rahardjo and B. C. Jiang, "Risk assessment of the critical production process using a new FMECA approach: an application in a cooking oil production company," in Proceedings of the 22nd ISSAT International Conference on Reliability and Quality in Design, Los Angeles, Calif, USA, August 2016.

[11] Y. Peng, S. Asgarpoor, W. Qiao et al., "Fuzzy cost-based FMECA for wind turbines considering condition monitoring systems," in Proceedings of the 2016 North American Power Symposium, pp. 1-6, IEEE, Denver, CO, USA, September 2016.

[12] D. Zhou, Y. Tang, and W. Jiang, "A modified model of failure mode and effects analysis based on generalized evidence theory," Mathematical Problems in Engineering, vol. 2016, Article ID 4512383, 11 pages, 2016.

[13] Y. Tang, J. Shu, W. Li, Y. He, Y. Yang, and P. Sun, “Quantitative risk evaluation model of the multilevel complex structure hierarchical system in the petrochemical industry," Mathematical Problems in Engineering, vol. 2019, Article ID 9328634, 12 pages, 2019.

[14] P. Lin, Q. Li, Q. Fan, X. Gao, and S. Hu, "A real-time locationbased services system using WiFi fingerprinting algorithm for safety risk assessment of workers in tunnels," Mathematical Problems in Engineering, vol. 2014, Article ID 371456, 10 pages, 2014.

[15] Y. Tang, Q. Liu, J. Jing, Y. Yang, and Z. Zou, "A framework for identification of maintenance significant items in reliability centered maintenance," Energy, vol. 118, pp. 1295-1303, 2017.

[16] A. Pillay and J. Wang, "Modified failure mode and effects analysis using approximate reasoning," Reliability Engineering \& System Safety, vol. 79, no. 1, pp. 69-85, 2003.

[17] B. Tchórzewska-Cieślak, "Bayesian model of urban water safety management," Global NEST Journal, vol. 16, no. 4, pp. 667-675, 2014.

[18] A. Irajpour, A. Fallahian-Najafabadi, M. A. Mahbod, and M. Karimi, "A framework to determine the effectiveness of maintenance strategies lean thinking approach," Mathematical Problems in Engineering, vol. 2014, Article ID 132140, 11 pages, 2014. 
[19] H. Fanghua and C. Guanchun, "A fuzzy multi-criteria group decision-making model based on weighted Borda scoring method for watershed ecological risk management: a case study of three gorges reservoir area of China," Water Resources Management, vol. 24, no. 10, pp. 2139-2165, 2010.

[20] K. Pietrucha-Urbanik and B. Tchórzewska-Cieślak, "Approaches to failure risk analysis of the water distribution network with regard to the safety of consumers," Water, vol. 10, no. 11, p. 1679, 2018.

[21] Y. Tang, Z. Zou, J. Jing, Z. Zhang, and C. Xie, "A framework for making maintenance decisions for oil and gas drilling and production equipment," Journal of Natural Gas Science and Engineering, vol. 26, pp. 1050-1058, 2015.

[22] B. Tchorzewska-Cieslak, "A fuzzy model for failure risk in waterpipe networks analysis," Ochrona Srodowiska, vol. 33, no. 1, pp. 35-40, 2011.

[23] S. Carpitella, A. Certa, J. Izquierdo, and C. M. La Fata, "A combined multi-criteria approach to support FMECA analyses: a real-world case," Reliability Engineering \& System Safety, vol. 169, pp. 394-402, 2018.

[24] Z. Haiyang, W. Jindong, J. Lee, and L. Ying, "A compound interpolation envelope local mean decomposition and its application for fault diagnosis of reciprocating compressors," Mechanical Systems and Signal Processing, vol. 110, pp. 273-295, 2018. 


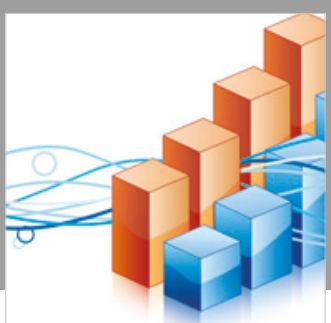

Advances in

Operations Research

\section{-n-m}
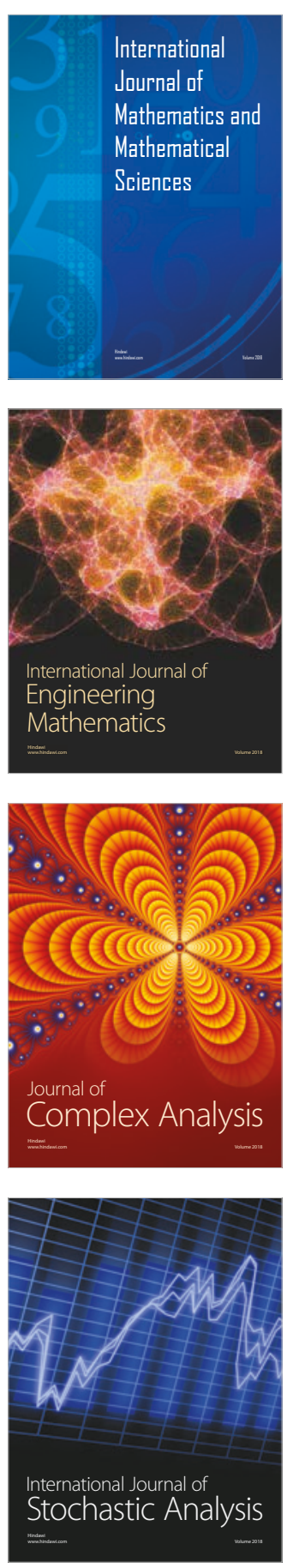
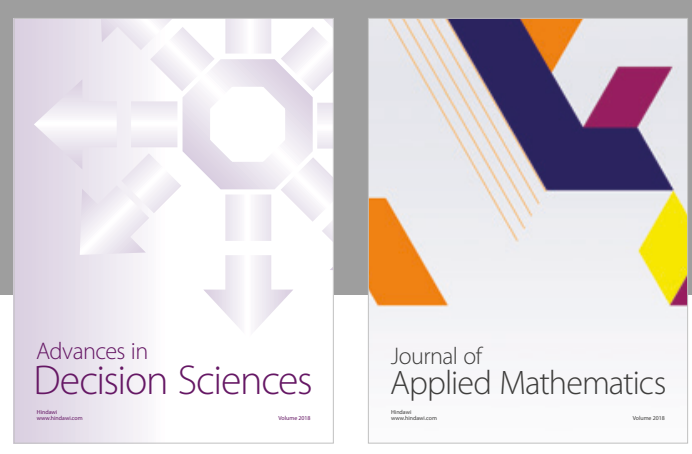

Journal of

Applied Mathematics
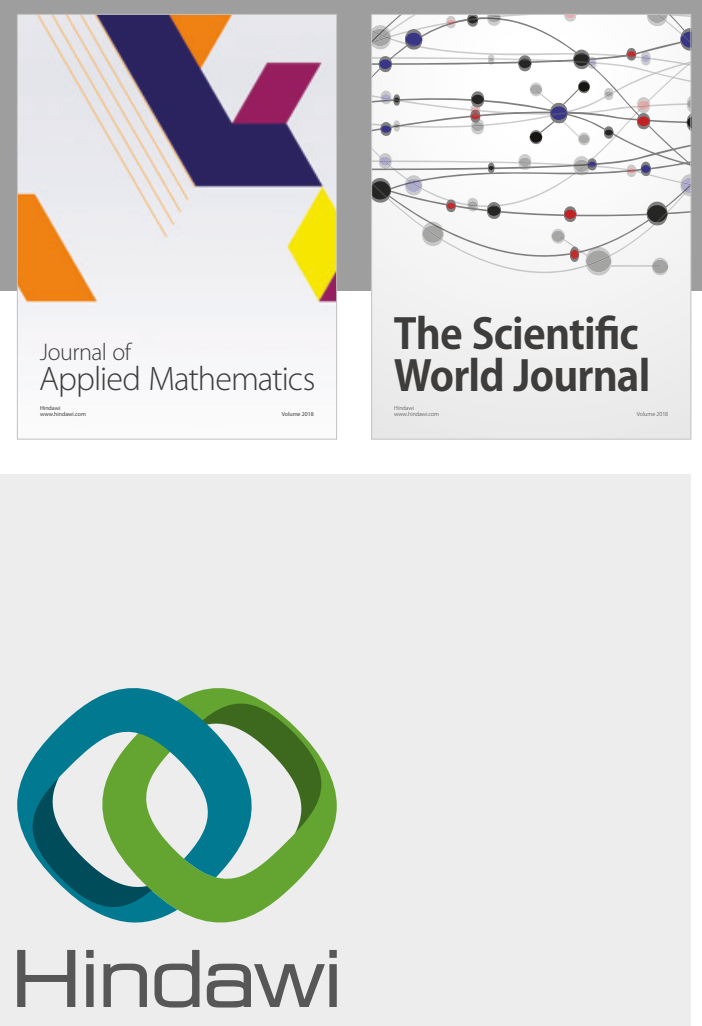

Submit your manuscripts at

www.hindawi.com

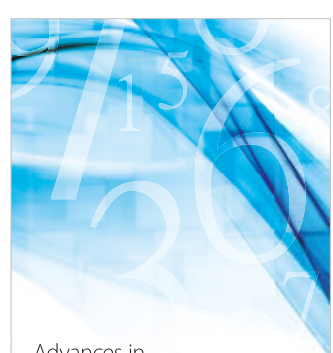

Advances in
Numerical Analysis
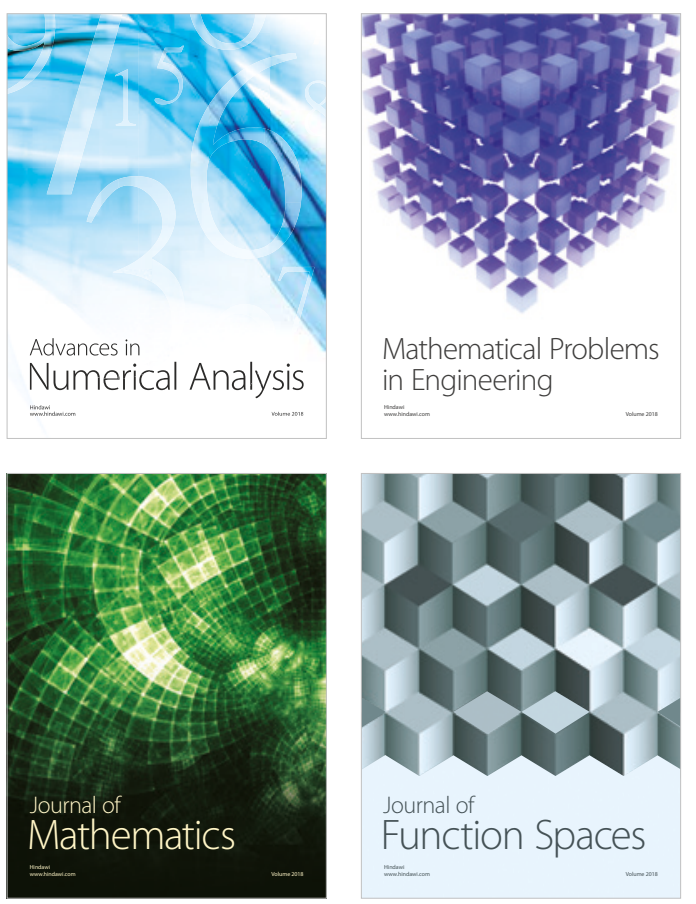

Mathematical Problems in Engineering

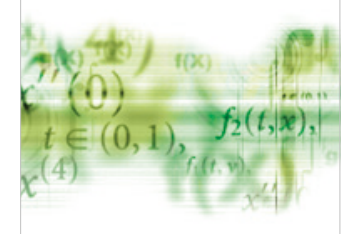

International Journal of

Differential Equations

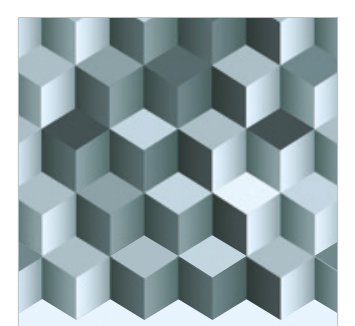

Journal of

Function Spaces

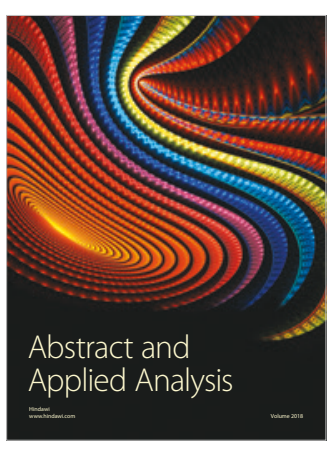

The Scientific

World Journal

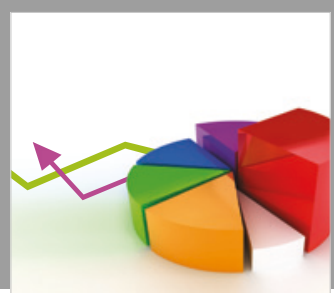

Journal of

Probability and Statistics
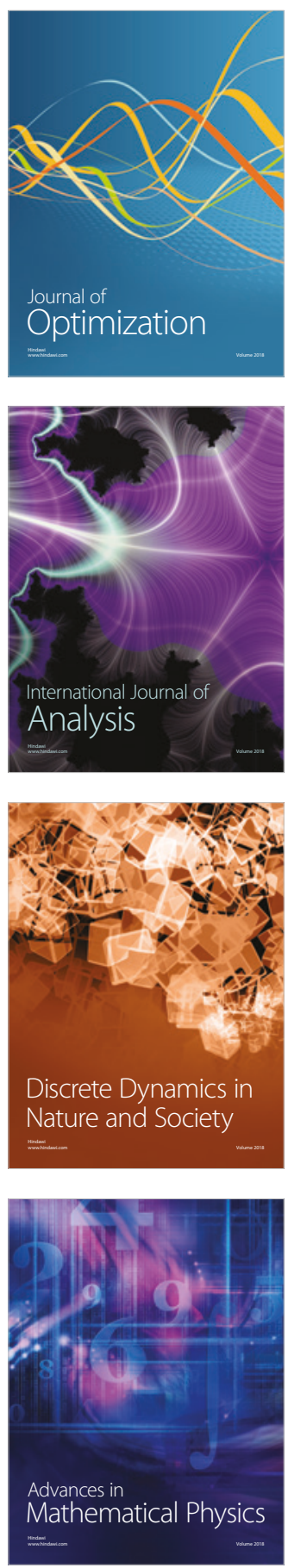